\title{
Tratamento temático da informação (TTI): influência dos paradigmas físico, cognitivo e social em artigos de revisão de literatura no período de 1966-1995
}

Information subject treatment: influence of the physical, cognitive and social paradigms in literature review articles in the period 19661995

\author{
Marisa Bräscher* \\ José Augusto Chaves Guimarães **
}

\section{RESUMO}

Propõe o estudo das influências dos paradigmas físico, cognitivo e social em pesquisas da área de Tratamento Temático da Informação (TTI) no período de 1966 a 1995, a partir de artigos de revisão publicados no Annual Review of Information Science (Arist). A pesquisa caracteriza-se como exploratória e emprega o método de revisão da literatura: umbrella review. O corpus de pesquisa é composto de 13 capítulos de revisão do estado da arte sobre TTI publicados no Arist, nas décadas de 19661995. Os três paradigmas estão presentes nas pesquisas de TTI relatadas nos artigos de revisão e observa-se maior evidência dos paradigmas físico e físico-cognitivo. Os paradigmas cognitivo e social foram evidenciados em apenas um artigo cada um. Conclui que o TTI acompanha as visões predominantes na ciência da informação quanto às influências epistemológicas.

Palavras-chave: Tratamento Temático da Informação; Paradigma Físico; Paradigma

\begin{abstract}
It proposes the study of the influences of the physical, cognitive and social paradigms in researches on Information Subject Treatment from 1966 to 1995 , based on review articles published in the Annual Review of Information Science (Arist). The research is characterized as exploratory and employs the literature review method umbrella review. The research corpus is composed of 13 state of the art reviews on Information Subject Treatment published in Arist in the decades of 1966-1995. The three paradigms are present in the TTI surveys reported in the review articles and there is more evidence of the physical and physical-cognitive paradigms. The cognitive and social paradigms were evidenced in only one article each. It concludes that the TTI accompanies the predominant visions in Information Science regarding epistemological influences.
\end{abstract}

Keywords: Information Subject Treatment; Physical Paradigm; Cognitive

\footnotetext{
${ }^{1}$ Agradecemos ao CNPq pelo apoio à realização desta pesquisa por meio de Bolsa de Produtividade de Pequisa.

* Doutora em Ciência da Informação. Professora associada da Universidade Federal de Santa Catarina. Endereço: Rua Engenheiro Agronômico Andrei Cristian Ferreira, s/n, Trindade, CEP 88040-900, Florianópolis, SC. Telefone: (48) 3721-2234. E-mail: marisa.brascher@gmail.com.

** Doutor em Comunicação. Professor titular da Universidade Estadual Paulista (Unesp/Marília). Endereço: Avenida Hygino Muzzi Filho, 737, Cx.P. 181, Campus Universitário, CEP 17525-900, Marília, SP. Telefone: (14) 3402-1336. E-mail: guima@marilia.unesp.br.
} 


\section{INTRODUÇÃO}

As questões relativas à análise, descrição e representação do conteúdo dos documentos inserem-se no contexto dos estudos da organização do conhecimento e constituem um desafio, em função da complexidade dos aspectos envolvidos nesses processos. Aqueles que se dedicam a essa área de pesquisa colocam-se frequentemente em contato com a problemática que envolve o que Baxendale (1966, p.75), no primeiro artigo de revisão do estado da arte sobre análise, especificação e controle de conteúdo publicado no Arist, denomina de "a Pandora's box of semantic and psychological complexities and unknowns". A mesma autora, ao finalizar o artigo e apontar visões para o futuro, observa que os trabalhos analisados por ela enfatizavam a exposição detalhada de cada procedimento e dispositivo de indexação estudado, o que demonstrava mais um reconhecimento de que "sabemos que não sabemos do que uma confirmação de que sabemos exatamente como encontrar a saída".

Passados 50 anos dessa reflexão, cabe questionar como a área de tratamento temático da informação (TTI), em sua busca pela compreensão e soluções para as questões de análise e representação temática, foi influenciada por paradigmas predominantes na ciência da informação. $O$ estudo aqui relatado direciona-se para a análise dos paradigmas físico, cognitivo e social e seus reflexos na pesquisa da área de TTI em três décadas (1966-1995). Para tanto, adotamos um método de revisão de literatura denominado umbrella review, que parte de revisões já realizadas. No caso desta pesquisa, aquelas publicadas no Annual Review of Information Science \& Technology (Arist), que fornecem um panorama geral do estado da arte, em áreas específicas da ciência da informação, em determinado período.

Este estudo é parte de uma pesquisa mais abrangente que visa analisar as tendências de pesquisas de TTI nas décadas de 1966-1995 em relação às desenvolvidas em décadas mais recentes (1996-2017). Nele apresentamos a análise da evolução dos estudos sobre o TTI, orientada pelo seguinte questionamento: entre os paradigmas físico, cognitivo e social, quais são os que mais influenciaram as pesquisas sobre o TTI no período 1966-1995? No intuito de encontrar respostas a esse questionamento, propomos como objetivo geral da pesquisa analisar a influência dos paradigmas físico, cognitivo e social na área de tratamento temático da informação evidenciadas em artigos de revisão da literatura internacional no período de 1966 a 1995, conforme retratada no Annual Review of Information Science (Arist). Como objetivos específicos: a) verificar a cobertura dada ao tema tratamento temático da informação no Arist no período 1966-1995; b) caracterizar os paradigmas físico, cognitivo e social na ciência da informação; c) coletar evidências sobre os paradigmas predominantes em cada período coberto pelos artigos de revisão.

Adotamos a denominação TTI nesta pesquisa na acepção sugerida por Barité (2001) que engloba a análise, descrição e representação do conteúdo dos documentos. Consideramos essa definição suficientemente abrangente para englobar os aspectos que pretendemos analisar, e evitamos assim as armadilhas terminológicas que podem levar a interpretações distintas daquela que adotamos quando nos referimos a documentos e seus conteúdos para fins de recuperação da informação. 


\section{TRATAMENTO TEMÁTICO DA INFORMAÇÃO (TTI)}

Como mencionamos na introdução deste artigo, optamos pelo uso do termo tratamento temático da informação, cientes de que não há uma concordância terminológica para se referir aos processos da organização do conhecimento (OC) relacionados ao conteúdo dos documentos. Assim, é necessário partir de uma compreensão sobre a abrangência do que chamamos de TTI. Para tanto, tomamos Foskett (1973) como ponto de partida e sua indagação sobre como podemos determinar o assunto de um documento de modo a especificá-lo. Sem pretender responder à questão, valemo-nos dessa pergunta para delimitar que o TTI abrange dois aspectos, o primeiro relacionado à determinação do assunto e o segundo à sua especificação.

Compreendemos que a distinção que fazemos entre o TTI e a descrição física por vezes não ocorre na prática do tratamento da informação, pois em certos contextos esses processos são realizados de maneira simultânea. De fato, o produto desses processos é a representação da informação, entendida como "um conjunto de elementos descritivos que representam os atributos de um objeto informacional específico de maneira a possibilitar a sua individualização e futura recuperação" (BRÄSCHER; CAFÉ, 2010, p.5). Porém, tanto a literatura da área quanto os pesquisadores que definem suas áreas de atuação caracterizam esses dois tipos de descrição como objetos de estudo distintos. É nesse mesmo entendimento que nosso interesse nesta pesquisa volta-se para os aspectos do TTI, mesmo que ao final o seu produto, a representação temática, componha, juntamente com a representação descritiva, uma única representação da informação.

Definida nossa visão sobre o TTI, que consideramos inserida no contexto dos estudos e pesquisas da organização do conhecimento, passamos a tratar do delineamento dos aspectos que fundamentam a análise a ser realizada sobre as pesquisas no período 1966-1995.

\section{INFLUÊNCIAS EPISTÊMICAS NO TTI}

Diante das inúmeras possibilidades de sistematizar as influências epistêmicas no TTI, apresentamos nesta seção as escolhas que orientam nosso olhar sobre as tendências observadas nos artigos de revisão do Arist, com o objetivo de identificar as que se evidenciam nos estudos em cada período analisado. Assumimos que o tratamento temático da informação sofre influência das posturas epistêmicas subjacentes, assim como ocorre na organização do conhecimento em geral, como afirma Tennis (2008, p. 103), "na OC nós formulamos enunciados epistêmicos sobre o conhecimento relativo aos conceitos, atos (como as representações), entidades e sistemas. Fazendo isso, criamos conhecimento, e nosso posicionamento epistêmico dita que tipo de conhecimento é esse".

Diversos autores tratam diferentes paradigmas e influências epistêmicas na ciência da informação e na OC: paradigma físico e cognitivo (ELLIS, 1992); paradigma físico, cognitivo e social (CAPURRO, 2003); empirismo, racionalismo, historicismo e pragmatismo (HJØRLAND 1998, 2003b); abordagem ontológica e epistemológica (GNOLI, 2008); modelo ontológico, gnosiológico e semiótico; cognitivismo, pragmatismo (GONZÁLEZ DE GOMEZ 1993, 1996) tradição representacionista pensamento essencialista-positivista, e tradição pragmatista -, pensamento retóricofilológico (SALDANHA, 2010); entre outros. 
Como sustenta Hjørland (1998 p. 611), “concepções e premissas na ciência da informação são influenciadas por visões metateóricas e epistemológicas". Sendo assim, para efeitos de nossa pesquisa, elaboramos uma síntese das características dos paradigmas físico, cognitivo e social e sua aproximação com determinadas visões epistemológicas, com base nos autores supracitados. Nosso objetivo não é discutir de maneira aprofundada cada um deles, e sim estabelecer parâmetros para o enquadramento das tendências observadas nos artigos de revisão segundo essas abordagens.

\section{Paradigma físico}

Segundo Ellis (1992, p. 50), os experimentos do projeto Cranfield, a partir de 1957, marcam o surgimento do paradigma físico e "a mudança de uma abordagem filosófica e teórica para uma experimental e empírica". O mesmo autor afirma que no paradigma físico "os sistemas de recuperação da informação (SRI) são vistos como sistemas físicos, tanto em relação à sua natureza quanto em relação às técnicas experimentais apropriadas a seu estudo" (ELLIS, 1992, p. 52). Nessa mesma direção, para Hjørland (1998, p. 611) o paradigma físico relaciona-se à tradição empirista, pois considera "a recuperação da informação como um processo objetivo e neutro" que pode ser medido pela precisão e revocação; e os assuntos dos documentos como uma "condensação semântica" do documento. Os assuntos, portanto, podem ser descritos pela extração de palavras do texto (HJØRLAND, 1998, p. 611).

A influência da teoria da informação de Shannon e Weaver é também associada a esse paradigma (CAPURRO, 2003; HJØRLAND 1998), assim como a "tradição representacionista" e o "positivismo otletiano" (SALDANHA, 2010, p. 305). A tradição representacionista

[...] tem a linguagem como meio, logo, como representação; tem o profissional que atua com a organização dos saberes como mediador; preocupa-se com a representação acurada dos signos, tendo para isso a lógica formal e a tecnologia que desta pode se desprender como modelo ideal ao otimizar a representação e sua dinâmica; aqui, o significado é visto como representação ideal de um termo, ou sua essência. Assim, o representacionismo comunga de um ponto de vista essencialista sobre a realidade. Busca-se aqui o significado como imago, a imagem definitiva, com uma universalidade expressa por uma relação lógica (SALDANHA, 2010, P. 311)

Esse paradigma caracteriza-se, ainda, pela exclusão "do papel ativo do sujeito cognoscente", do usuário (CAPURRO, 2003) e, portanto, o TTI orienta-se com foco na análise temática e extração do assunto, e na sua representação por meio de algum tipo de vocabulário controlado.

Em nossa análise, enquadramos nessa abordagem epistêmica os artigos de revisão que: relacionam o TTI ao processo de recuperação da informação com ênfase nos procedimentos experimentais, operacionais e de desenvolvimento dos sistemas de recuperação; avaliam a qualidade do TTI com base em medidas de eficácia da recuperação da informação, como precisão e revocação; adotam uma visão centrada no sistema e seus dispositivos, incluindo-se aí as linguagens de indexação; utilizam métodos estatísticos e de processamento automático da linguagem natural para extração de assuntos e indexação automática; defendem soluções orientadas para padronização e representação universal do conhecimento; voltam-se para a definição 
de normas e padrões para o TTI, esse último visto a partir de uma visão orientada ao documento.

\section{Paradigma cognitivo}

A premissa básica do paradigma cognitivo é de que os sistemas de informação apoiam-se num modelo mental da realidade. Apesar de não possuir um construto tão marcante como é o projeto Cranfield para o paradigma físico (ELLIS 1992), a teoria do estado anômalo do conhecimento de Belkin costuma ser associada ao paradigma cognitivo (ELLIS, 1992; HJØRLAND, 1998; CAPURRO, 2003). O ano de surgimento desse paradigma também não pode ser precisado como no paradigma anterior, mas situa-se a partir da década de 1980, quando

[...] os estudos da informação se voltam ao problema da relação significado-informação, com objetivos diversos: melhorar os SRI e as formas de representação do conhecimento; incorporar a variável cultural na programação de ações locais e internacionais de transferência da informação e, finalmente, fazer frente às condições de interface entre as máquinas e os textos, entre os códigos binários e palavras, incluindo-se nesta linha desde o processamento automático da linguagem até as formas mais sofisticadas dos sistemas especialistas e a inteligência artificial (GONZÁLEZ DE GOMEZ, 1996, p. 45).

As pesquisas no paradigma físico caracterizam-se por sua homogeneidade de objetivos e métodos, o que contrasta fortemente com as pesquisas no paradigma cognitivo, que têm diversidade de objetivos e métodos, mas se unem por considerarem que os sistemas de recuperação da informação refletem em suas operações, de alguma maneira, o mundo cognitivo do usuário (ELLIS, p. 53).

Como destaca González de Gomez (1993, p.221), na abordagem cognitivista, um modelo de usuário orienta "a representação, busca e absorção da informação, simulados em sistemas homens-máquina". Essa abordagem, portanto, como esclarece Hjørland (1998, p. 611), relaciona o assunto dos documentos ao conhecimento e necessidades individuais dos usuários e "trata a informação como um objeto que preenche uma lacuna no conhecimento do usuário". Há uma influência do racionalismo nas pesquisas que se aproximam desse paradigma.

No paradigma cognitivo, o profissional da informação atua no sentido de construir os modelos de intermediação entre o usuário e o sistema, já não é ele o próprio mediador, mas o responsável por compreender o modelo mental do usuário e adaptá-lo em modelos artificiais que servem de interface com o usuário final. O TTI sob a influência do paradigma cognitivo é realizado no sentido de corresponder ao modelo cognitivo do usuário, e a elaboração das representações temáticas visa reproduzir esse modelo. Portanto, o enfoque do paradigma cognitivo nos artigos de revisão analisados nesta pesquisa é observado com base nas seguintes características: foco na interface homem-máquina dos sistemas de recuperação da informação; utilização de modelos mentais da realidade para o desenho de sistemas de informação; preocupação com as linguagens de interação com o usuário (linguagem de indexação e linguagem de busca); análise do comportamento dos usuários para a modelagem dos sistemas de recuperação da informação (SRI); adaptação do TTI a modelos de comportamento do usuário; ênfase na formulação de estratégia de busca e sua relação com as representações da informação; aplicação de 
sistemas especialistas na recuperação da informação; busca pela compreensão do julgamento de relevância para reproduzir o modelo do usuário.

\section{Paradigma social}

Enquanto no paradigma cognitivo, o usuário é percebido sob "perspectiva individualista e isolacionista", no paradigma social ele é visto "dentro de um contexto social" (CAPURRO, 2003). Esse contexto influencia também "as trocas de informação no quadro das relações sociais e suas figuras de cooperação e de conflito" (GONZÁLEZ DE GOMEZ, 1993, p. 221).

Apesar de surgir a partir de meados dos anos 1990 como um paradigma recente, sua influência na área de informação, como destacam Capurro (2003) e Saldanha (2010), relaciona-se à proposta da Epistemologia Social de Shera e Egan, e, portanto, "o paradigma social já se encontrava no início, se bem que não como paradigma da ciência da informação, mas sim de seus predecessores, em particular a biblioteconomia e a documentação" (CAPURRO, 2003).

A nova roupagem do paradigma social conecta-se, sobretudo, aos trabalhos de Hjørland e sua proposta de um "paradigma sociológico epistemológico" (HJØRLAND, 1998), ou perspectiva sociocognitiva (HJØRLAND; ALBRETCHESEN, 1995; HJØRLAND, 2003a), a qual

[...] reconhece que um documento pode servir a diferentes propósitos para diferentes grupos de usuários (ou indivíduos em diferentes situações. A análise de assunto não deve ser vista como universal ou individual, mas deve sim refletir os grupos-alvo dos sistemas de informação. O mesmo documento pode receber diferentes descrições de assunto quando comparamos sua representação numa biblioteca médica e numa biblioteca militar (HJØRLAND, 2003a, p. 611).

Capurro (2003) contextualiza o paradigma social levando em conta o paradigma hermenêutico, a semiótica, o construtivismo e a cibernética de segunda ordem. HJØRLAND (2003a) o conecta ao historicismo e ao pragmatismo quando afirma que "propósitos específicos demandam uma perspectiva mais pragmática, enquanto propósitos gerais demandam uma perspectiva mais realista. Minha visão está conectada ao historicismo" (HJØRLAND, 2003a, p. 611).

Como observa Saldanha (2010, p. 311), sob o olhar do pragmatismo são "os usos sociais" que conferem "significados aos artefatos e às palavras". Sendo assim, os conceitos são entendidos como construções sociais e não universais. Capurro (2003) salienta ainda que os dados registrados em sistemas de informação devem ser concebidos como "oferta frente a qual o usuário desempenha papel eminentemente ativo", papel esse que se relaciona aos "interesses prévios à busca" influenciados pela "rede social e pragmática que os sustentam".

Nesta pesquisa, para possibilitar a identificação da influência do paradigma cognitivo nos artigos de revisão, entendemos que, sob essa perspectiva, o TTI é realizado levando em conta determinadas comunidades discursivas; os usuários são tidos como sujeitos ativos que interagem e atuam em determinados contextos sociais que influenciam suas demandas de informação e a maneira como se relacionam com os ambientes informacionais; os processos de análise temática admitem a subjetividade e as múltiplas possibilidades de interpretação dos conteúdos a partir dos seus usos sociais; as linguagens de representação temática apoiam-se em diferentes visões da 
realidade e, ao refletir os múltiplos contextos socioculturais das comunidades discursivas, reconhecem e respeitam a diversidade linguística.

Ao sintetizar as três perspectivas epistêmicas, reconhecemos as limitações que se apresentam quando tentamos enquadrar a realidade em parâmetros predefinidos e, ainda, o fato de que as influências epistêmicas convivem e por vezes se complementam nos estudos da ciência da informação. No entanto, acreditamos ser possível, a partir da escolha desses três olhares, traçar um panorama geral sobre suas influências nas pesquisas de TTI no período analisado nesta pesquisa.

Entendemos que há uma certa cronologia que marca a presença mais forte dos três paradigmas nos estudos da ciência da informação em determinados períodos, pois, como afirma Capurro (2003), "a ciência da informação nasce em meados do século XX com um paradigma físico, questionado por um enfoque cognitivo idealista e individualista, sendo por sua vez substituído por um paradigma pragmático e social". González de Gomez (1996) indica o surgimento do paradigma cognitivo na década de 1980 e, apesar do caráter social já estar manifestado em estudos da biblioteconomia e documentação, o seu reconhecimento como paradigma se fortalece em meados da década de 1990. Nosso objetivo não é estabelecer ou corroborar alguma cronologia, até mesmo porque, como dito anteriormente, influências epistemológicas convivem nas pesquisas da área. No entanto, se levarmos em conta que o período de nossa pesquisa é de 1966 a 1995, nossa expectativa é encontrar uma predominância do paradigma físico em relação aos demais, e talvez haja pouca ou nenhuma influência dos paradigmas cognitivo e social evidenciada nesse período de cobertura da literatura.

Ainda há muito a ser discutido e consolidado com respeito às bases epistemológicas do TTI, e outros enfoques ou abordagens que não foram aqui discutidos certamente podem ser relevantes. Mas, tomamos o que foi aqui proposto como ponto de partida para direcionar nosso estudo.

Assim como Guimarães (2009, p.106), consideramos que a questão relacionada ao conteúdo

[...] emerge como um ponto fundamental a ser abordado, assumindo papel estratégico em arquivos, bibliotecas e museus, enquanto instituições coletoras de cultura (HOMULOS, 1990). Isso ocorre em virtude de sua capacidade de agregar valor ao conhecimento, "notadamente em termos de conteúdo uma vez que o documento, enquanto registro de conhecimento, passa a ser o de representante ou substituto de idéias [sic] e criações", refletindo aquilo que Cubillo (1999, p. 17) denomina surrogate of knowledge, ou seja, um substituto do conhecimento gerado por alguém que normalmente não pode estar presente.

Dessa maneira, a compreensão da evolução do TTI pode revelar aspectos relevantes que contextualizam o desenvolvimento dessa área e tornam as escolhas epistêmicas mais evidentes em determinados contextos de pesquisa. Tendo situado em linhas gerais as bases teóricas sobre as quais apoiaremos nossa pesquisa, apresentamos na seção seguinte a metodologia do estudo. 


\section{METODOLOGIA}

A pesquisa é exploratória e emprega o método de revisão da literatura denominado umbrella review ${ }^{2}$ em português revisão guarda-chuva, que compila as evidências de outras revisões de literatura, sem recorrer à literatura primária. É um método que possibilita analisar o que é conhecido e o que permanece desconhecido sobre determinada temática, e pode, ainda, propor recomendações para pesquisas futuras (GRANT; BOOTH, 2009; THE JOANNA BRIGGS INSTITUTE, 2014).

O corpus de análise são as revisões de estado da arte publicadas sobre TTI no Arist, periódico publicado pela American Society for Information Science (Asis). 0 levantamento dos artigos de revisão foi realizado nos sumários dos volumes 1 (1966) a 30 (1995). Como resultado, obtivemos 13 revisões de literatura sobre TTI publicadas no Arist nesse período, cujas referências estão listadas no Apêndice I. Além dos artigos de revisão, analisamos os prefácios de cada volume e a introdução da seção específica em que os capítulos estão inseridos.

Os artigos de revisão do Arist são fontes de pesquisa inestimáveis para os pesquisadores da ciência da informação e áreas correlatas. Infelizmente, o Arist deixou de ser publicado, tendo sido o volume 45, relativo ao ano 2011, o último produzido. Cronin (2011, p.vii), no prefácio desse volume ressalta que "o Arist foi perene para o campo: possui autoridade, é confiável e abrangente". A qualidade do Arist e seu reconhecimento na área nos leva a tomá-lo como fonte única de coleta do material necessário para retratar as pesquisas realizadas no período de análise desta pesquisa.

É necessário ressaltar que estamos cientes do possível viés da visão dos autores dos artigos de revisão, em função de variáveis subjetivas, como sua formação e experiência profissional, temática de pesquisa a qual se dedicam, entendimento sobre o processo de TTI. No entanto, esse aspecto não foi considerado nesta pesquisa e nos valemos do fato dos capítulos de revisão, conforme destacado na introdução do seu primeiro volume (CUADRA, 1966), serem apoiados por uma bibliografia exaustiva compilada pela equipe do Arist. Além disso, os revisores são escolhidos por critérios que valorizam sua expertise, capacidade de se manterem atualizados e de produzir sínteses e críticas sobre as pesquisas relatadas na literatura. Acreditamos, portanto, que os autores não poderiam ir numa direção totalmente contrária ou que não refletisse as temáticas presentes na literatura da área. Assim sendo, entendemos que os capítulos do Arist revelam o estado da arte das pesquisas em cada período coberto pelas revisões e fornecem evidências das tendências observadas à época.

\section{A ÁREA DE TRATAMENTO TEMÁTICO DA INFORMAÇÃO NAS REVISÕES DO ARIST (1966-1995)}

No período de 1966 a 1989, a área de TTI é contemplada ininterruptamente no Arist, pois, apesar de não haver artigo específico sobre o tema nos anos 1975, 1976, 1978, 1979, 1980, 1981, 1983, 1984, 1985, 1987 e 1988, os artigos publicados cobriram o período em anos subsequentes às lacunas de artigos. Os volumes 1 e 2 não são organizados em seções e os capítulos intitulam-se "Content analysis representation

\footnotetext{
${ }^{2}$ Esse método de revisão é também conhecido como "overviews of reviews, reviews of reviews, a summary of systematic reviews and also a synthesis of reviews" (THE JOANNA BRIGGS INSTITUTE, 2014).
} 
and control". A partir do ano de 1968, volume 3, surge a seção II denominada "Basic techniques and tools". O tema do capítulo, nos anos de 1968 e 1969, intitula-se "Content analysis, specification and control" e dedica-se especificamente ao TTI. Em 1970, o capítulo passa a ser intitulado "Document descrition and representation" e permanece até 1974 com cobertura dos aspectos da descrição física e do TTI conjuntamente. Após o ano de 1974, há lacunas na publicação de artigos anuais sobre o tema no Arist, conforme já afirmado. O capítulo reaparece publicado no ano de 1977 (cobre os anos 1975 e 1976) e retoma o escopo da revisão inicial ao tratar apenas a área de TTI, com o título "Subject analysis" e assim é publicado nos anos de 1982 (contempla o período 1977-1981), 1986 (abrange o período 1982-1985) e 1989 (cobertura de 1986-1988). Na década de 1990, não há mais capítulos que englobam a área como um todo e na mesma seção II, cujo título muda para "Basic techniques and Technologies", são publicados artigos em diversos temas relacionados ao recorte dado a essa seção do Arist.

Observamos que as temáticas da seção II tornam-se mais específicas a partir de 1990, talvez pela expansão da área e dificuldade de abranger uma subárea quase autônoma como o TTI. Entre os capítulos temáticos da seção II, apenas um direciona-se a uma temática mais próxima ao TTI, publicado em 1994, cujo título é "Digital image representation and acess". Esse capítulo não foi incluído em nossa pesquisa em função de sua cobertura ser em tema específico, o que poderia comprometer a visão geral do TTI almejada na pesquisa. Assim sendo, para a revisão guarda-chuva analisamos os 13 artigos de revisão da literatura que cobrem a área como um todo (Cf. Apêndice I).

A análise foi realizada à luz dos paradigmas físico, cognitivo e social, conforme as sínteses propostas na seção "Influências epistêmicas no TTI", e orienta-se para a identificação das tendências evidenciadas nos artigos de revisão, a partir da visão geral do processo de TTI, e não sobre aspectos específicos de cada pesquisa reportada. Nosso direcionamento é produzir um panorama com base no exposto pelos autores das revisões, como objetiva uma umbrella review.

\section{RESULTADOS}

A análise dos artigos de revisão sobre o TTI no Arist nos permitiu observar que as pesquisas que compõem as revisões realizam-se sob diferentes perspectivas epistêmicas. No entanto, a aderência a um ou outro paradigma, como é objetivo identificar nesta pesquisa, levou em conta o que é evidenciado pelos autores de cada revisão e os aspectos expostos na seção "Influências epistêmicas no TTI" deste artigo.

O Quadro 1 apresenta a caracterização das tendências observadas quanto às influências percebidas em cada ano de publicação dos artigos de revisão. Em função das evidências encontradas nos artigos, sentimos a necessidade de criar uma categoria intermediária para efeito de sistematização dos resultados, a qual denominamos de paradigma físico-cognitivo. Nela abrigamos os artigos que tratam com maior ênfase o papel do usuário no TTI e nos SRI, mas ainda apresentam soluções de concepção, desenvolvimento e teste de sistemas de informação mais condizentes com o paradigma físico. 
Quadro 1 - Influência dos paradigmas no TTI.

\begin{tabular}{|c|c|c|c|c|c|c|c|c|c|c|c|c|c|}
\hline PARADIGMA & 1966 & 1967 & 1968 & 1969 & 1970 & 1971 & 1972 & 1973 & 1974 & 1977 & 1982 & 1986 & 1989 \\
\hline $\begin{array}{c}\text { Paradigma } \\
\text { físico }\end{array}$ & $\mathrm{X}$ & $\mathrm{X}$ & & & & & $\mathrm{X}$ & & $\mathrm{X}$ & & & & \\
\hline $\begin{array}{c}\text { Paradigma } \\
\text { físico-cognitivo }\end{array}$ & & & $\mathrm{X}$ & & $\mathrm{X}$ & $\mathrm{X}$ & & $\mathrm{X}$ & & $\mathrm{X}$ & $\mathrm{X}$ & $\mathrm{X}$ & \\
\hline $\begin{array}{c}\text { Paradigma } \\
\text { cognitivo }\end{array}$ & & & & & & & & & & & & & $\mathrm{X}$ \\
\hline $\begin{array}{c}\text { Paradigma } \\
\text { social }\end{array}$ & & & & $\mathrm{X}$ & & & & & & & & & \\
\hline
\end{tabular}

Fonte: produção dos autores.

Observa-se no Quadro 1, que no período 1966-1989 houve maior influência do paradigma físico e cognitivo, com sete artigos de revisão que evidenciam esse posicionamento, seguido do paradigma físico em quatro artigos e dos paradigmas cognitivo e social, que se destacam em apenas um dos artigos cada um. Selecionamos alguns extratos dos textos dos artigos, expostos nos Quadros 2, 3, 4 e 5, que são representativos da tendência observada nos artigos de revisão e que corroboram o enquadramento realizado. 
Quadro 2 - Extratos dos artigos sob influência do paradigma físico.

\begin{tabular}{|c|c|}
\hline ANO & PARADIGMA FÍSICO - EXTRATOS \\
\hline & $\begin{array}{l}\text { p. } 71 \text { - "Uma grande proporção da literatura, aproximadamente um terço tratam de estudos empíricos e } \\
\text { experiências na compilação de índices e classificações em áreas específicas do conhecimento." } \\
\text { p. } 88 \text { - "Dadas todas as possíveis escolhas sintáticas e semânticas disponíveis para descrever o conteúdo, } \\
\text { que procedimentos e dispositivos normativos podem melhorar a consistência na descrição e reduzir a } \\
\text { ambiguidade na interpretação para ambos, sistema e usuários?" } \\
\text { p. } 88 \text { - "A necessidade de controle terminológico está implícita no termo linguagem de indexação." } \\
\text { p. } 88 \text { - Percebe-se a busca por "procedimentos e dispositivos normativos para melhoria da consistência da } \\
\text { descrição e redução da ambiguidade na interpretação do sistema e do usuário" e na "prescrição de regras } \\
\text { explícitas para a sintaxe das entradas dos índices", uma vez que "a normalização semântica é mais } \\
\text { complexa." }\end{array}$ \\
\hline & $\begin{array}{l}\text { p. } 90 \text { - "Desde que a "recuperação da informação" entrou na moda, há uma busca contínua por uma pedra } \\
\text { filosofal que resolva o problema de uma vez por todas, uma busca em formular a "teoria" da recuperação. } \\
\text { O ano em revisão não viu redução nessa busca." } \\
\text { p. } 91 \text { - "Como todo o trabalho no campo da recuperação da informação tem por objetivo principal a } \\
\text { melhoria da performance, a diminuição dos custos, ou ambos, a tese de que há uma relação inversa entre a } \\
\text { revocação e a precisão deve ser tratada com ênfase, pois se é verdadeira, parece não haver outro propósito } \\
\text { na pesquisa sobre performance, exceto nos permitir escolher melhor o ponto da curva no qual esperamos } \\
\text { que determinado sistema funcione." } \\
\text { p. } 89 \text { - "Essa é uma tendência, voltar para trás e examinar os métodos tradicionais de indexação e } \\
\text { elaboração de resumos com vistas a isolar seus aspectos principais de maneira que as máquinas possam } \\
\text { ser empregadas para simular a metodologia envolvida e assim encontrar os mesmos resultados." }\end{array}$ \\
\hline & $\begin{array}{l}\text { p. } 69 \text { - "Como as necessidades atendidas por um documento variam muito, a descrição em si tende a variar } \\
\text { em forma e complexidade, a ausência de uniformidade apresenta problemas para seus usuários. Alguns } \\
\text { progressos têm sido feitos recentemente no sentido de produzir descrições documentais mais uniformes: } \\
\text { pressões econômicas e relacionadas à centralização e automação levaram a uma grande aceitação da ideia } \\
\text { da uniformidade." } \\
\text { p. } 74 \text { - "Idealmente, todos os documentos devem ser descritos uniformemente de maneira que o usuário } \\
\text { possa compreender e usar o sistema. A padronização e a codificação orientam-se para esse objetivo. } \\
\text { Grande parte da seção sobre a representação documental trata desse objetivo e seu atingimento." } \\
\text { p. } 87 \text { - "Classificações especializadas são necessárias para coleções especiais. No entanto, apesar das } \\
\text { dificuldades, a classificação universal ainda é necessária em bibliotecas que tratam todo o universo do } \\
\text { conhecimento. A busca por um sistema que seja melhor do que os atuais continua." } \\
\text { p. } 88 \text { - "A inclusão numa classe não se relaciona à interpretação intuitiva das palavras. Nenhum } \\
\text { questionamento é feito durante o processo. As metodologia que usam esse tipo de classificação baseiam- } \\
\text { se na lógica matemática, na inferência estatística e outros meios probabilísticos." } \\
\text { p. } 91 \text { - "Um interesse renovado na metodologia do experimento Cranfield II..." }\end{array}$ \\
\hline & $\begin{array}{l}\text { p. } 81 \text { - "Padronização domina os trabalhos de descrição documental e, em menor extensão, a } \\
\text { representação, no ano de } 1973 . " \text { Os esforços mais significativos são internacionais, com os trabalhos } \\
\text { regionais ou nacionais geralmente direcionados para a compatibilidade com os padrões internacionais. O } \\
\text { controle bibliográfico internacional, somado ao intercâmbio bibliográfico, é o objetivo e maior motivação } \\
\text { desses trabalhos." } \\
\text { p. } 81 \text { - "Desde os dias da Royal Society Catalogue e a falha dos esforços do Instituto Internacional de } \\
\text { Bibliografia para manter seus arquivos de fichas dos papers técnico científicos, o sonho da bibliografia } \\
\text { internacional parecia estar morto. Nos anos recentes, no entanto, ele ressuscitou gradualmente e se tornou } \\
\text { mais vigoroso; o tema da conferência da IFLA em Grenoble em } 1973 \text { foi controle bibliográfico." } \\
\text { p. } 109 \text { - "Na representação de assunto, os esforços estão em andamento, não para padronizar, mas para } \\
\text { tornar os vocabulários de indexação compatíveis. A motivação é a mesma da padronização: minimizar a } \\
\text { duplicação de esforços e aumentar a "recuperabilidade" dos documentos. Os trabalhos relatados abordam } \\
\text { tentativas relativas a: compatibilidade de vocabulários e/ou indexação..." }\end{array}$ \\
\hline
\end{tabular}

Fonte: elaborado pelos autores a partir dos artigos do corpus da pesquisa listados no Apêndice. 
Os extratos exemplificam características que nos levam a perceber a influência do paradigma físico, como a natureza empírica e experimental dos estudos, preocupação com a definição de regras e procedimentos normativos, busca por interpretações unívocas, crença na formulação "da" teoria da recuperação, centralidade no sistema e sua performance, avaliação da qualidade do TTI com base nas medidas de precisão e revocação propostas no Projeto Cranfield, defesa das representações universais do conhecimento, e adoção de métodos matemáticos, estatísticos e probabilísticos.

Destacamos que essa tendência está atrelada ao contexto em que se desenvolviam as pesquisas à época, um período de transição dos meios tradicionais para os sistemas "mecanizados" de informação, em que houve contribuição de engenheiros e outros profissionais com formação em áreas mais próximas das ciências exatas no desenvolvimento de SRI. Certamente isso trouxe influências ao enfoque dado às pesquisas em TTI, sobretudo se levarmos em conta a sua relação de proximidade com a recuperação da informação, tanto na pesquisa quanto na prática.

O Quadro 3 a seguir apresenta os extratos que ilustram os artigos nos quais observamos características dos paradigmas físico e cognitivo, conforme expostos na seção "Influências epistêmicas no TTI", e que, portanto, categorizamos como paradigma físico e cognitivo.

Quadro 3 - Extratos dos artigos sob influência do paradigma físico e cognitivo.

\begin{tabular}{|c|c|}
\hline ANO & PARADIGMA FÍSICO E COGNITIVO \\
\hline & $\begin{array}{l}\text { p. } 107 \text { - "Muitos trabalhos tratam de teste e avaliação de um sistema e há uma tentativa de definir medidas } \\
\text { de performance e estabelecer critérios para avaliar e justificar os investimentos." } \\
\text { p. } 128 \text { - "Coletivamente [os trabalhos da área] poderão proporcionar evidências adicionais, por meio de } \\
\text { experiências operacionais, testes, avaliações e desenvolvimento de modelos, que certas práticas são } \\
\text { apropriadas e úteis." } \\
\text { p. } 128 \text { - "É certo que não só no próximo ano, mas nos posteriores, veremos uma ênfase crescente no estudo } \\
\text { da parceria homem-máquina nos sistemas de armazenamento e recuperação de informação, para fazer uso } \\
\text { máximo da capacidade heurística inerente do homem e a capacidade algorítmica inerente do computador. } \\
\text { lsto será resultado o fato de que a comunidade da área de tratamento da informação tem sido incapaz de } \\
\text { determinar ou predizer o comportamento individual e coletivo dos usuários, reagindo ou operando um } \\
\text { sistema [...] consequentemente, há ainda mais necessidade de compreender melhor o modo interativo de } \\
\text { acesso e acompanhar a capacidade de browsing." }\end{array}$ \\
\hline & $\begin{array}{l}\text { p. } 144 \text { - "A literatura de } 1969 \text { reflete a preocupação em compreender e melhorar o processo de indexação } \\
\text { para incrementar a eficácia do indexador humano. O problema foi abordado por meio de estudos empíricos } \\
\text { que aplicam métodos e testam sua eficácia e por meio de análise racional dos fatores que afetam a } \\
\text { indexação humana." } \\
\text { p. } 161 \text { - "A pergunta foi colocada sob nova perspectiva como um importante fator que afeta a indexação e } \\
\text { há uma consciência sobre a necessidade de maior integração entre as atividades de indexação, busca e } \\
\text { controle de vocabulário." } \\
\text { p. } 161 \text { - "Talvez o aspecto mais importante da literatura de } 1969 \text { é o insight geral de que as operações de } \\
\text { indexação, busca e controle de vocabulário não podem ser vistas como atividades isoladas e que sistemas } \\
\text { bem desenhados devem considerar sua integração." }\end{array}$ \\
\hline
\end{tabular}




\begin{tabular}{|c|c|}
\hline & $\begin{array}{l}\text { p. } 134 \text { - "Necessitamos de mais estudos estatísticos sobre o uso real dos diferentes elementos incluídos em } \\
\text { sistemas que atendem a vários objetivos, de maneira que o desenho desses sistemas possa ser otimizado." } \\
\text { p. } 137 \text { - "Concluindo, consideramos as funções de recuperação da representação documental. } \\
\text { Primeiramente, cada representação é preparada num contexto particular de um sistema de informação, } \\
\text { desenvolvido para servir às necessidades de determinado grupo de usuários." } \\
\text { p. } 137 \text { - "Como as perguntas dos usuários variam em suas necessidades de revocação e precisão, um fator } \\
\text { essencial nos sistemas de recuperação é a flexibilidade da estratégia de busca." }\end{array}$ \\
\hline & $\begin{array}{l}\text { p. } 44 \text { - "A descoberta da busca online é algo que está modelando a representação de itens em coleções } \\
\text { amplas e gerais. Se a iteração é fácil, o armazenamento textual e a recuperação são baratos, o usuário não } \\
\text { está mais na desvantagem de ter que especificar as suas necessidades em um perfil horrível [awful profile } \\
\text { commitment ]. A representação documental, portanto, deve ser mais ajustada e a logística da estrutura da } \\
\text { coleção se torna tão importante quanto o conteúdo dos itens componentes." } \\
\text { p. } 48 \text { - "Talvez no nível "universal", o termo não deva fazer mais do que direcionar subconjunto de } \\
\text { documentos nos índices especializados apropriados, nos quais podem ser indexados de maneira que } \\
\text { correspondam às necessidades e linguagem dos usuários." } \\
\text { p. } 63 \text { - "Não escapamos ainda do quebra nozes revocação/precisão; não resolvemos ainda a extensão com } \\
\text { que a semântica ou a estatística devem respectivamente moldar nossos registros. Estamos longe ainda de } \\
\text { saber onde a máquina deve sair e a leitura deve começar." }\end{array}$ \\
\hline & $\begin{array}{l}\text { p. } 82 \text { - "O mesmo [a padronização]não ocorre com a análise de assunto. Como veremos a seguir no } \\
\text { panorama da área, atividades teóricas, experimentais e de desenvolvimento ainda abundam na área de } \\
\text { análise de assunto. Ainda estamos a um longo, muito longo caminho de converter a arte da análise de } \\
\text { assunto numa tecnologia altamente sistematizada com normas amplamente aceitas." } \\
\text { p. } 102 \text { - "[...] o problema da análise de assunto está intrinsecamente relacionado com a compreensão de } \\
\text { como pensamos, criamos, comunicamos, armazenamos, salvamos para uso futuro e usamos conceitos e os } \\
\text { reusamos em combinações e permutações de maneira ilimitada para sintetizar ou conceber novos conceitos. } \\
\text { É um ciclo intrigante." } \\
\text { p. } 102 \text { - "Se há uma fragilidade na pesquisa em andamento na área é a falha em compreender a verdadeira } \\
\text { complexidade. Devemos tentar, de maneira organizada, integrar o conhecimento aplicável que está sendo } \\
\text { gerado em várias disciplinas. Esse aprimoramento da análise de assunto vai demandar tempo e paciência, } \\
\text { mas o objetivo é intrigante, pois se relaciona de maneira muito próxima à maneira como pensamos." }\end{array}$ \\
\hline & $\begin{array}{l}\text { p. } 126 \text { - "O problema do controle terminológico é impor padrões a uma linguagem dinâmica e em crescimento [...] } \\
\text { O controle terminológico utilizando bancos terminológicos é uma nova área de desenvolvimento [...] Parte do } \\
\text { problema envolvido na padronização do termo é a escolha do "melhor" termo para representar o conceito." } \\
\text { p. } 127 \text { - "Mesmo sem uma base teórica integrada e aceita, o controle terminológico é amplamente usado." } \\
\text { p. } 143 \text { - "Com o advento dos sistemas interativos em linha, os limites entre a indexação e a busca estão } \\
\text { incrivelmente tênues. De fato, como as tentativas de medir a eficácia da indexação nos últimos } 20 \text { anos } \\
\text { demonstram, elas são inseparáveis, e a interação em linha reforça essa fusão. Não é surpresa que as áreas de } \\
\text { pesquisa mais ativas neste momento são fortemente ligadas a essa interdependência. Nessa rubrica, incluímos } \\
\text { muitos dos estudos sobre controle terminológico, compatibilidade de linguagens de indexação, atribuição de } \\
\text { pesos aos termos de indexação a partir dos feedbacks de relevância. No entanto, o efeito total dessa } \\
\text { interdependência nos padrões de pesquisa e na maneira como pensamos sobre problemas de recuperação ainda } \\
\text { está se desdobrando." }\end{array}$ \\
\hline 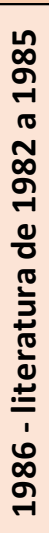 & $\begin{array}{l}\text { p. } 48 \text { - "A área de tratamento estatístico de textos apresenta maior número de publicações do que todas as } \\
\text { outras áreas dessa revisão combinadas. Isso é resultado da disponibilidade em larga escala de software e } \\
\text { base de dados legíveis por computador e uma saudável cooperação entre os pesquisadores. Reflete } \\
\text { também, depois de } 30 \text { anos de trabalho, uma identificação mais clara dos esforços frutíferos e uma } \\
\text { abordagem mais sistemática de testes e experimentações." } \\
\text { p. } 50 \text { - "A literatura discutida na revisão representa cerca de } 30 \% \text { do total produzido no período. Esse } \\
\text { interesse não é surpresa diante dos desenvolvimento em OPACs, software e hadware de } \\
\text { microcomputadores, e apoio tecnológico a aplicações estatísticas em larga escala. Os esforços dessas } 3 \\
\text { áreas revelaram as deficiências dos meios e usos tradicionais da descrição de assunto, em particular onde } \\
\text { usuários finais não estão treinados." } \\
\text { p. } 50 \text { - "Maior esforço ainda é necessário para compreender o comportamento humano durante a busca por } \\
\text { assunto, uma vez que o processo que consideramos lógico e auto-evidente na busca por informação, não é } \\
\text { aparentemente visto dessa maneira pelos usuários." }\end{array}$ \\
\hline
\end{tabular}

Fonte: elaborado pelos autores a partir dos artigos do corpus da pesquisa listados no Apêndice. 
Os extratos selecionados permitem notar que ainda permanecem a centralidade no sistema e o uso da abordagem empírica e experimental com a preocupação de avaliar a performance da recuperação da informação e, assim, encontrar a melhor maneira de realizar o tratamento temático da informação, sistematizando normas e padrões. No entanto, já no ano de 1968 o autor da revisão alerta para a tendência dos estudos se voltarem para a interface homem-máquina e para analisar o comportamento dos usuários, pois esse aspecto não estava sendo observado no desenho dos sistemas. Essa perspectiva corrobora-se nos anos posteriores, das décadas de 1970 e início de 1980, em que os contextos específicos de busca por determinados usuários ou grupos de usuários passam a ser levados em conta. Esse contexto - os sistemas especializados - já coloca em cheque o uso de sistemas ou representações universais. Se há uma aderência ao paradigma cognitivo que traz à tona a necessidade de levar em conta a maneira como pensamos, nos comportamos e usamos informação, há também aderência ao paradigma físico na abordagem dessas questões, numa procura pela sistematização e transformação em normas amplamente aceitas de TTI. Talvez isso seja uma característica do momento de transição vivido pela área, em virtude dos desafios apresentados pelo ambiente online das bases de dados bibliográficos. Nota-se essa perspectiva já mais consolidada no artigo de 1989, único enquadrado no paradigma cognitivo, como revelam os extratos do quadro 4.

\section{Quadro 4 - Extratos do artigo sob influência do paradigma cognitivo.}

\begin{tabular}{|c|c|}
\hline ANO & PARADIGMA COGNITIVO \\
\hline 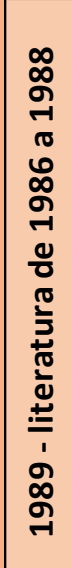 & $\begin{array}{l}\text { p.35 - "Análise de assunto significa a presença, identificação e expressão do assunto em textos de } \\
\text { documentos, bases de dados, linguagens controlada e natural, solicitações de informação e estratégias de } \\
\text { busca. Sob o ponto de vista do usuário, análise de assunto está fortemente ligada ao acesso ao assunto." } \\
\text { p. } 36 \text { - Citando Saracevic et al (1988) "há uma conexão óbvia e talvez mais pontes devam ser construídas } \\
\text { entre a pesquisa e a prática da indexação e a pesquisa e a prática da busca." } \\
\text { p. } 36 \text { - "Aboutness é um conceito escorregadio. O assunto de um documento algumas vezes é visto como } \\
\text { um aboutness instrínseco. Variáveis tais como "para que um documento pode ser usado", "porque ele foi } \\
\text { obtido", dentre outras variáveis externas, são vistas como aboutness extrínseco." } \\
\text { p. } 48 \text { - "A busca pelo usuário final tem se tornado mais comum com o aumento do uso de computadores } \\
\text { pessoais e há mais e mais bases de dados em CDROM." } \\
\text { p. } 51 \text { - "A busca feita pelo usuário final, ao menos em alguns ambientes, requer uma interface amigável ao } \\
\text { usuário para que o processo de busca seja o mais simples possível." } \\
\text { P. } 54 \text { - "A eficácia da busca delegada depende muito de como uma requisição feita pelo usuário reflete a } \\
\text { sua necessidade de informação. Muito trabalho tem sido produzido sobre a interação com o usuário." }\end{array}$ \\
\hline
\end{tabular}

Fonte: Elaborado pelos autores a partir dos artigos do corpus da pesquisa listados no Apêndice.

O artigo do ano de 1989 abrange o período 1986 a 1988, em que a consolidação do ambiente de busca online parece trazer o usuário final de maneira mais evidente. 0 comportamento e necessidades dos usuários passam a ser destacados na concepção e desenvolvimento dos sistemas de recuperação da informação, o que traz consequências também para o tratamento temático da informação, que passa a se ajustar a essas demandas. Já há sinais de que esse olhar volta-se também para outras variáveis externas, como o "aboutness extrínseco", o que pode ser um sinal da visão defendida pelo paradigma social. Sobre esse último, o Quadro 5 ilustra os extratos do artigo de revisão do volume 4 , de 1969, em que percebemos a influência da vertente tradicional do paradigma social, aquela mais ligada à epistemologia social e aos estudos da biblioteconomia e da documentação. 
Quadro 5 - Extratos do artigo sob influência do paradigma social.

\begin{tabular}{|c|c|}
\hline ANO & PARADIGMA SOCIAL \\
\hline $\begin{array}{l}\text { જூ } \\
\text { જ̆ } \\
\text { ન్- }\end{array}$ & $\begin{array}{l}\text { p. } 73 \text { - "Os bibliotecários e seus dispositivos existem apenas para auxiliar os leitores a encontrar o que os } \\
\text { outros disseram." } \\
\text { p. } 73 \text { - "Eles [os bibliotecários] devem criar métodos que permitam aos leitores especificarem o tipo de } \\
\text { discurso que desejam, e fornecer rótulos (label) que antecipem essa especificação." } \\
\text { p. } 74 \text { - "A segunda tarefa inatíngivel é o bibliotecário ou sistema substituir o leitor na seleção dos } \\
\text { documentos. Para fazer isso, ele deve ser o próprio leitor, na sua hereditariedade, história, emoções, } \\
\text { interesses, intelecto, e até no que ele odeia comer no café da manhã." } \\
\text { p. } 76 \text { - "Julgamentos sobre o conteúdo são apoiados em evidências do texto, do documento ou da } \\
\text { solicitação e são realizados em contraste com um cenário - implícito ou explícito - de experiência social." } \\
\text { p. } 98 \text { - "Muitos trabalhos não foram incluídos porque não mereceram menção, pois demonstram uma } \\
\text { ignorância sobre a diferença entre manipulação de objetos rotulados e a elaboração e atribuição de rótulos } \\
\text { para vários fins sociais." }\end{array}$ \\
\hline
\end{tabular}

Fonte: Elaborado pelos autores a partir dos artigos do corpus da pesquisa listados no Apêndice.

O artigo produzido por Fairthorne (1969) foi o único em que o paradigma social se destaca. No entanto, é preciso ressaltar o caráter crítico do artigo de Fairthorne, que expõe sua visão direcionada ao papel social dos bibliotecários e de suas atividades. Não podemos afirmar que essa visão se reflete no conjunto de pesquisas que o artigo abrange, mas sobretudo no enfoque dado à revisão pelas ideias expressas pelo autor. $\mathrm{O}$ artigo de Fairthorne revela que, mesmo não sendo o ponto de vista dominante à época, havia um conjunto de pesquisadores cientes do aspecto social das ações informacionais.

A análise dos 13 artigos de revisão da literatura que compuseram nosso corpus de análise nos permitiu observar que os paradigmas físico, cognitivo e social influenciaram as pesquisas de TTI e, como exige a boa prática acadêmica, os pesquisadores direcionaram seus olhares a partir de determinados posicionamentos epistêmicos e, dessa maneira, conviveram defendendo seus pontos de vista sobre a área e as possíveis maneiras de enfrentar os desafios colocados.

\section{CONSIDERAÇÕES FINAIS}

Em nossa pesquisa, procuramos identificar a influência dos paradigmas físico, cognitivo e social conforme destacada nos artigos de revisão da literatura sobre TTI do Arist, no período de 1966 a 1995. Os três paradigmas estão presentes nas pesquisas de TTI relatadas nos artigos de revisão no período analisado. No entanto, os paradigmas físico e físico e cognitivo foram os que apresentaram maior evidência nos artigos analisados, o que reflete nossa crença no início da pesquisa - de que o TTI acompanha as visões predominantes na ciência da informação naquele período.

Os paradigmas cognitivo e social foram evidenciados em apenas um artigo cada um. Sobre o primeiro, ressaltamos que, apesar deste trabalho não ter por objetivo analisar os temas específicos tratados em cada artigo de revisão, não podemos deixar de observar que o paradigma cognitivo se fez mais presente em pesquisas de indexação automática que empregam representações do conhecimento. Podemos afirmar que essa não foi uma perspectiva que teve grande impacto em outros aspectos do TTI, conforme exposto nos artigos analisados. Sobre esse aspecto, porém, devemos lembrar que Ellis (1992, p. 55) destaca a "dificuldade de identificar as pesquisas [no paradigma cognitivo], devido à sua origem e campos de aplicação 
difusos, sendo também difícil identificar "exemplares amplamente aceitos". Portanto, esse é um aspecto que precisa ser investigado em mais profundidade.

Sobre o paradigma social, conforme visto, ele foi evidenciado em sua vertente tradicional no artigo de Fairthorne (1969). É interessante notar que esse é o único artigo em que a autora utiliza o termo "leitor", e não "usuário" ou "pesquisador", como preferem os demais artigos e, também, o único em que o papel social do bibliotecário é levado em conta no contexto do TTI. Certamente a voz dessa autora, assim como de outros pesquisadores que atuaram no período analisado, ecoaram e frutificaram no pensamento mais recente da ciência da informação e da organização do conhecimento, em que se observa ampla repercussão do paradigma social.

Os artigos de revisão refletem o impacto da tecnologia, num momento de transição do ambiente estritamente manual para o "mecanizado", percebido sobretudo nos artigos de 1966 a 1977 e, posteriormente, o ambiente já automatizado, mais presente nos artigos da década de 1980. Na literatura retratada nos artigos de revisão fica evidente a forte aproximação das pesquisas sobre TTI com as da recuperação da informação, em que as discussões se dão principalmente no contexto dos sistemas de informação, e não no das bibliotecas tradicionais. Diante desse contexto, talvez possamos compreender melhor as escolhas epistêmicas que se apresentaram como as mais naturais.

Para finalizar, deixamos registrado o quanto foi rica essa viagem no tempo e a percepção dos movimentos, pensamentos, problemáticas e contexto de pesquisa vigentes à época. Percebemos o fascínio pelas possibilidades oferecidas pela tecnologia, que se apresentava como um remédio para todos os males. Foi possível captar, ainda, um certo desencantamento em alguns períodos, pois, os que se dedicam ao TTI como tema de pesquisa conhecem a complexidade de seus aspectos, mais ligados ao humano e social do que ao tecnológico. Quem sabe, assim como nesta pesquisa, os pesquisadores da área daqui há 50 anos possam olhar para as pesquisas realizadas atualmente e refletir sobre nossos posicionamentos. $O$ que dirão sobre nosso fascínio atual?

\section{REFERÊNCIAS}

BARITÉ, M. Organización del conocimiento: un nuevo marco teórico-conceptual en Bibliotecología y Documentación. In: CARRARA, K. (Org.). Educação, universidade e pesquisa. Marília: Unesp-Marília-Publicações; São Paulo: Fapesp, 2001. p.35-60.

BAXENDALE, P. Content analysis, specification, and control. Annual Review of Information Science (Arist), v.1, p. 71-105, 1966.

BRÄSCHER, M.; CAFÉ, L. Organização da informação ou organização do conhecimento?. In: ENCONTRO NACIONAL DE PESQUISA EM CIÊNCIA DA INFORMAÇÃO, 9., 2008, São Paulo. Anais eletrônicos... São Paulo: USP, 2008.

CAPURRO, R. Epistemologia y ciencia de la información. In: ENCONTRO NACIONAL DE PESQUISA EM CIÊNCIA DA INFORMAÇÃO, 5., 2003, Belo Horizonte. Anais... Belo Horizonte: Escola de Ciência da Informação da UFMG, 2003.

CRONIN, B. Introduction. Annual Review of Information Science (Arist), v.45, p. vii-xxiii, 2011.

CUADRA, A.C. Introduction to the ADI Annual Review. Annual Review of Information Science (Arist), v.1, p. 1-11, 1966. 
ELLIS, D. The physical and cognitive paradigms in information retrieval research. Journal of Documentation, v.48, n.1, p. 45-64, 1992.

FAIRTHORNE, R. A. Content analysis, specification, and control. Annual Review of Information Science (Arist), v.4, p. 73-109, 1969.

FOSKETT, A. C. A abordagem temática da informação. São Paulo: Polígono, 1973.

$\mathrm{GNOLI}, \mathrm{C}$. Ten long-term research questions in knowledge organization. Knowledge. Organization, v.35, n. 2, p.137-149, 2008.

GONZÁLEZ DE GÓMEZ, M. N. A representação do conhecimento e o conhecimento da representação: algumas questões epistemológicas. Ciência da Informação, Brasília, v. 22, n. 3, p. 217-222, set./dez. 1993.

. Comentários ao artigo "Hacia um nuevo pardigma em bibliotecologia". Transinformação, Campinas, v. 8, n. 3, p. 44-56, set./dez. 1996.

GRANT, M. J.; BOOTH, A. A typology of reviews: an analysis of 14 review types and associated methodologies. Health Information and Libraries Journal, v.26, p.91-108, 2009.

GUIMARAES, J. A. C. Abordagens teóricas de tratamento temático da informação (TTI): catalogação de assunto, indexação e análise documental. In: GARCÍA MARCO, F. J. (Coord.). Avances y perspectivas en sistemas de información y documentación. Zaragoza: Prensas de La Universidad de Zaragosa, 2009. p. 105-117.

HJØRLAND, B. Epistemology and the socio-cognitive perspective in information science. Journal of the American Society for Information Science and Technology, v.53, n. 4, 257-270, 2003 .

. Fundamentals of knowledge Organization. Knowledge Organization, v.30, n.2, p.87-111, 2003b.

. Theory and metatheory of information science: a new interpretation. Journal of Documentation, v. 45, n. 5, 606-621, 1998.

HJØRLAND, B.; ALBRECHTSEN, H. Toward a new horizont in information science: domain analysis. Journal of the American Society for Information Science, v. 46, n. 6, p. 400-425, jul.1995.

JOANNA BRIGGS INSTITUTE. Joanna Briggs Institute Reviewers' Manual: 2014 edition / supplement. Adelaide: The Joanna Briggs Institute, 2014.

SALDANHA, G.S. Tradições epistemológicas nos estudos de organização dos saberes: uma leitura histórico-epistêmica a partir da filosofia da linguagem. Liinc em Revista, Rio de Janeiro, v. 6, n. 2, p. 300-315, set. 2010.

TENNIS, T.T. Epistemology, theory, and methodology in knowledge organization: toward a classification metatheory, and research framework. Knowledge Organization, v.35, n.2/3, p.102$112,2008$.

\section{APÊNDICE - ARTIGOS QUE COMPÕEM O CORPUS DE PESQUISA}

BAXENDALE, P. Content analysis, specification, and control. Annual Review of Information Science (Arist), v.1, p. 71-105, 1966.

SHARP, J.R. Content analysis, specification, and control. Annual Review of Information Science (Arist), v.2, p. 87-122, 1967. 
TAUBEE, O.E. Content analysis, specification, and control. Annual Review of Information Science (Arist), v.3, p. 105-136, 1968.

FAIRTHORNE, R. A. Content analysis, specification, and control. Annual Review of Information Science (Arist), v.4, p. 73-109, 1969.

ARTANDI, S. Document description and representation. Annual Review of Information Science (Arist), v.5, p. 143-167, 1970.

VICKERY, B. Document description and representation. Annual Review of Information Science (Arist), v.6, p. 113-140, 1971.

RICHMOND, P. A. Document description and representation. Annual Review of Information Science (Arist), v.7, p. 73-102, 1972.

BATTEN, W. E. Document description and representation. Annual Review of Information Science (Arist), v.8, p. 43-67, 1973.

HARRIS, J. L. Document description and representation. Annual Review of Information Science (Arist), v.9, p. 81-117, 1974

LISTON JR.; MURRAY, L. H. Subject analysis. Annual Review of Information Science (Arist), v.12 p. 81-118, 1977.

TRAVIS, I.; RAYA, F. Subject analysis. Annual Review of Information Science (Arist), v.17, p. 123-157, 1982.

SCHWARTZ,C. ; EISENMANN, L. M. Subject analysis. Annual Review of Information Science (Arist), v.21, p.37-61, 1986.

LANCASTER, F. W; ELLIKER, C.; CONNELL, T. H.. Subject analysis. Annual Review of Information Science (Arist), v.24, p. 35-83, 1989. 